\title{
Physician-to-physician telephone consultations for chronic pain patients: A pragmatic randomized trial
}

\author{
Alexander J Clark MD FRCPC, Paul Taenzer PhD, Neil Drummond PhD, \\ Christopher C Spanswick MB ChB FRCA FFPMRCA, Lori S Montgomery MD CCFP, Ted Findlay DO CCFP, \\ John X Pereira MD CCFP, Tyler Williamson PhD, Luz Palacios-Derflingher PhD, Ted Braun MD CCFP FCFP
}

\begin{abstract}
AJ Clark, P Taenzer, N Drummond, et al. Physician-to-physician telephone consultations for chronic pain patients: A pragmatic randomized trial. Pain Res Manag 2015;20(6):288-292.
\end{abstract}

BACKGROUND: The impact of telephone consultations between pain specialists and primary care physicians regarding the care of patients with chronic pain is unknown.

OBJECTIVES: To evaluate the impact of telephone consultations between pain specialists and primary care physicians regarding the care of patients with chronic pain.

METHODS: Patients referred to an interdisciplinary chronic pain service were randomly assigned to either receive usual care by the primary care physician, or to have their case discussed in a telephone consultation between a pain specialist and the referring primary care physician. Patients completed a numerical rating scale for pain, the Pain Disability Index and the Short Form-36 on referral, as well as three and six months later. Primary care physicians completed a brief survey to assess their impressions of the telephone consultation.

RESULTS: Eighty patients were randomly assigned to either the usual care group or the standard telephone consultation group, and 67 completed the study protocol. Patients were comparable on baseline pain and demographic characteristics. No differences were found between the groups at six months after referral in regard to pain, disability or quality of life measures. Eighty percent of primary care physicians indicated that they learned new patient care strategies from the telephone consultation, and $97 \%$ reported that the consultation answered their questions and helped in the care of their patient.

DISCUSSION: Most primary care physicians reported that a telephone consultation with a pain specialist answered their questions, improved their patients' care and resulted in new learning. Differences in patient status compared with a usual care control group were not detectable at six-month follow-up.

CONCLUSIONS: While telephone consultations are clearly an acceptable strategy for knowledge translation, additional strategies may be required to actually impact patient outcomes.

Key Words: Chronic pain; Consultation; Knowledge translation; Primary care; Specialist; Telephone

\section{Les consultations téléphoniques entre médecins pour les patients atteints de douleur chronique : un essai aléatoire pragmatique}

HISTORIQUE : On ne connaît pas les effets des consultations télépho-
niques entre spécialistes de la douleur et médecins traitants au sujet des
soins des patients atteints de douleur chronique.
OBJECTIFS : Évaluer l'effet de consultations téléphoniques entre spé-
cialistes de la douleur et médecins traitants au sujet des patients atteints de
douleur chronique.
MÉTHODOLOGIE : Les patients dirigés vers un service interdiscipli-
naire de gestion de la douleur chronique étaient attribués au hasard entre
les soins habituels du médecin traitant ou une consultation téléphonique
de leur cas entre un spécialiste de la douleur et le médecin traitant. Les
patients ont rempli une échelle d'évaluation numérique de la douleur,
l'indice d'incapacité causé par la douleur et le formulaire court en 36 ques-
tions lors de l'aiguillage, puis trois et six mois plus tard. Les médecins trai-
tants ont répondu à un bref sondage pour évaluer leurs impressions de la
consultation téléphonique. RÉSULTATS : Quatre-vingts patients ont été répartis au hasard entre le groupe de soins habituels ou le groupe de consultation téléphonique standardisé, et 67 ont terminé le protocole d'étude. Les patients partageaient une douleur et des caractéristiques démographiques comparables en début d'étude. Six mois après l'aiguillage, les chercheurs n'ont constaté aucune différence entre les groupes quant aux mesures de la douleur, de l'incapacité ou de la qualité de vie. De plus, $80 \%$ des médecins traitants précisaient avoir découvert de nouvelles stratégies de soins des patients grâce à la consultation téléphonique, et $97 \%$ signalaient que la consultation avait répondu à leurs questions et contribué aux soins du patient.

EXPOSÉ : La plupart des médecins traitants déclaraient avoir obtenu les réponses à leurs questions lors d'une consultation téléphonique avec un spécialiste de la douleur, ce qui leur permettait d'améliorer leurs soins et d'acquérir de nouveaux apprentissages. L'état des patients lors du suivi au bout de six mois ne différait pas de celui du groupe témoin ayant reçu les soins habituels.

CONCLUSIONS : De toute évidence, les consultations téléphoniques constituent une stratégie acceptable pour le transfert du savoir, mais il faudra peut-être adopter d'autres stratégies pour parvenir à de réels résultats cliniques chez les patients.
Chronic pain is a common health condition $(1,2)$, whose prevalence and impact will continue to increase as the population ages (3). Pain is the subject of one in three primary care visits (4); however, primary care physicians (PCPs) report lacking confidence and expertise in managing it (5). This gap between patient need and providers' ability has been attributed to a lack of training, access to guidelines and tools supporting best practice $(6,7)$.

While there is a growing consensus that the most complex chronic pain cases are best cared for by tertiary care multidisciplinary teams $(8,9)$, access to these is a barrier. Most teams are located in urban centres and have an average wait time of six months (7). Wait times of this duration (referral to treatment) are associated with adverse quality of life and mental health outcomes (10).

Most chronic pain care will continue to be provided in primary care settings, hence, the importance of developing and implementing strategies for assisting PCPs with pain-related best practices. One such strategy is direct consultation between pain specialists and PCPs without the patient being present; a 'curbside consultation' $(11,12)$.

University of Calgary, Calgary, Alberta

Correspondence: Dr Alexander J Clark, Pain Management Unit, 4th Floor Dickson, QEIIHSC, 5820 University Avenue, Halifax,

Nova Scotia B3H 1V7. Telephone 902-473-6428, fax 902-473-4126, e-mail ajohn.clark@nshealth.ca 
The present study used a pragmatic, randomized experimental design to explore whether telephone consultations with pain specialists were acceptable to PCPs and led to benefits for patients compared with wait list controls. The trial was registered at www.clinicaltrials.gov (NCT01923324).

\section{METHODS}

Research questions

For the comparison of 'usual care' (UC), with care that included a 'standard telephone consultation' (STC) between patients' PCPs and a pain specialist, the following questions were addressed:

1. Were there changes in patient outcomes?
a. Pain
b. Perceived disability
c. Quality of life

2. Is it acceptable?

a. Is STC perceived as a knowledge transfer strategy by the PCP b. Is the PCP satisfied

3. Do resource requirements of the Chronic Pain Centre (CPC) change?

\section{Eligibility}

Patients were eligible for the present study if they were referred to the Alberta Health Services Calgary CPC with neurological or musculoskeletal chronic pain, they met the CPC's referral criteria (chronic pain of $>3$ months' duration, not a Workers Compensation client) and were competent in English to complete study questionnaires. Patients were excluded if: they were at increased risk for suicide; they had a very complex case; the referring PCP could not reliably identify the patient's pain problem; or their condition warranted expedited CPC consultation. Patients at possible increased risk for suicide were identified using the Center for Epidemiologic Studies Depression Scale Revised (eg, "I wish I were dead" and "I wanted to hurt myself"), and very complex cases (eg, widespread pain associated with very significant psychiatric or psychological disease) were identified using the preassessment questionnaire patients were asked to complete after referral to the CPC.

All PCPs and patients included in the study provided consent to participate.

\section{Sample size}

A sample of 100 patients (50 per group), assuming 20\% attrition to follow-up, was calculated as being able to detect a minimally clinically relevant difference between the groups for a mean pain score on the numerical rating scale (NRS) of $>2$, with $80 \%$ power at the $5 \%$ significance level.

\section{Outcome measures}

Outcome measures included an NRS for pain intensity (13), the Pain Disability Index (PDI) (14), the Short Form (SF)-36 Health Survey (15), a seven-point Patient Global Impression of Change scale, the Pain Treatment Satisfaction Scale (16), a PCP satisfaction questionnaire and a knowledge transfer questionnaire. Resource use at the CPC comparing UC with STC was estimated using the CPC's resource use tracking system.

\section{Intervention}

For patients randomly assigned to the STC group, the telephone consultation was scheduled at a time mutually convenient for both the PCP and the pain specialist, shortly after referral was received at the $\mathrm{CPC}$. The consultation followed a semistructured interview format designed to: clarify the PCP's goals and expectations of treatment; review the pain problem; consider relevant comorbidity and previous pain treatment; and make suggestions for future pain management by the PCP. Immediately following the consultation, the pain specialist dictated a summary of proceedings and faxed it, along with appropriate treatment protocols and patient information materials, to the PCP.
TABLE 1

Patient characteristics at baseline

\begin{tabular}{lccc}
\hline Characteristic & STC group $(\mathbf{n}=\mathbf{4 1})$ & UC group $(\mathbf{n}=\mathbf{3 7})$ & $\mathbf{P}^{*}$ \\
\hline Age, years & $49.5 \pm 12.5$ & $49.6 \pm 11.4$ & 0.974 \\
Female sex, \% & 65.9 & 59.5 & 0.466 \\
NRS average pain & $6.3 \pm 1.6$ & $6.9 \pm 1.5$ & 0.101 \\
NRS worst pain & $7.9 \pm 1.5$ & $8.2 \pm 1.6$ & 0.504 \\
NRS least pain & $4.1 \pm 2.0$ & $5.1 \pm 2.6$ & 0.065 \\
NRS current pain & $6.1 \pm 1.9$ & $6.7 \pm 2.3$ & 0.217 \\
PDI total & $38.6 \pm 13.9$ & $40.8 \pm 12.3$ & 0.449 \\
SF-36 PF & $31.4 \pm 10.5$ & $29.4 \pm 12.2$ & 0.445 \\
SF-36 RP & $28.7 \pm 9.3$ & $28.1 \pm 9.8$ & 0.780 \\
SF-36 BP & $29.5 \pm 5.9$ & $29.2 \pm 5.1$ & 0.843 \\
SF-36 GH & $38.2 \pm 10.5$ & $38.0 \pm 10.9$ & 0.920 \\
SF-36 VT & $37.5 \pm 10.5$ & $37.4 \pm 9.6$ & 0.979 \\
SF-36 SR & $32.9 \pm 9.9$ & $29.7 \pm 9.5$ & 0.161 \\
SF-36 RE & $38.0 \pm 12.9$ & $37.0 \pm 13.5$ & 0.725 \\
SF-36 MH & $41.3 \pm 11.3$ & $40.2 \pm 10.0$ & 0.665 \\
SF-36 physical summary & $29.2 \pm 7.5$ & $28.5 \pm 8.0$ & 0.661 \\
SF-36 mental summary & $42.0 \pm 12.0$ & $40.8 \pm 10.9$ & 0.644 \\
\hline Data present as mean & SD &
\end{tabular}

Data presented as mean $\pm S D$ unless otherwise indicated. ${ }^{*} P$ values are from $\mathrm{t}$ tests for all comparisons, except the sex comparison, which was performed using z test. BP Bodily pain; GH General health perceptions; MH Mental health; NRS Numerical rating scale; PDI Pain Disability Index; PF Physical functioning; RE Emotional role functioning; RP Physical role functioning; $S F$ Short form; SR Social role functioning; STC Standard telephone consultation; UC Usual care; VT Vitality

The PCP could use this information as he/she saw fit for the best care of the patient. A routine follow-up telephone call, in a semi-structured interview format designed to clarify the patient's progress, as well as to problem solve and refine the management recommendations between the two physicians, was scheduled three months after the structured telephone consultation. At the six-month follow-up telephone call, the PCP was asked specific questions regarding the process, satisfaction with the process and perceived knowledge transfer.

Patients randomly allocated to the UC group received an appointment for assessment by a CPC pain specialist approximately six months after randomization, which was representative of normal referral wait times. The UC group did not receive any additional information from the CPC.

Outcome assessments were collected from both patient groups at three and six months. Patients were blinded as to group assignment.

\section{Study design}

Patients were allocated to either the UC or STC group using a random permutated block design, with assignments contained in opaque, numbered envelopes held by the study coordinator. Cases assigned to the STC group were the subject of a telephone discussion between the pain specialist and the referring PCP. Cases assigned to the UC group were entered into normal CPC wait list processes.

Baseline assessment of outcome was derived from the routine preassessment questionnaire completed by all CPC patients. End point data collection was collected using self-completed mail surveys for all patients and physicians consenting to participate in the study.

Clinical outcomes were measured three and six months after the STC for the STC group, and at three months after referral and at the time of CPC assessment for the UC group (approximately six months after referral). PCP satisfaction was recorded after each STC contact. The present study was approved by the Conjoint Health Research Ethics Board at the University of Calgary (Calgary, Alberta).

\section{RESULTS}

Eighty subjects were recruited for the present study, and two withdrew (one from each group). The research database contained 78 subjects (41 in the STC group and 37 in the UC group). Characteristics of 


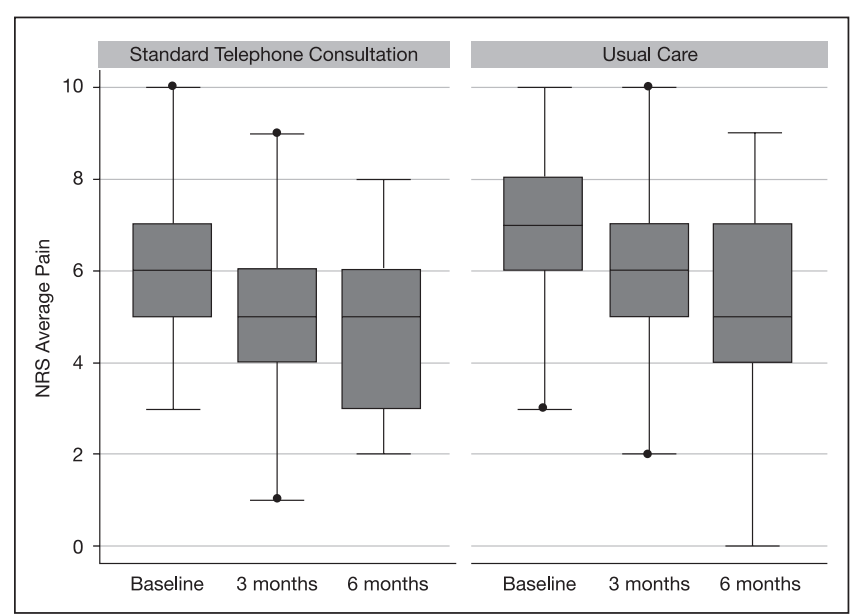

Figure 1) Numerical rating scale (NRS) for average pain at baseline, three and six months. Boxplots provide the median (centre line), first (lower box edge) and third (upper box edge) quartiles, as well as the upper and lower adjacent values (at the end of each whisker). Dots represent values $>1.5 \times$ the interquartile range away from the median

patient participants are provided in Table 1. A full complement of 100 subjects was unable to be collected due to funding and time restraints.

Were there changes in patient outcomes?

NRS average pain: Both groups demonstrated a modest, but insignificant, decrease in pain (according to the NRS) over the study period (Figure 1). The mean reduction in average pain score at three months was 0.91 for the STC group and 0.79 for the UC group $(\mathrm{P}=0.708$ [ $t$ test]). At six months the reduction was 0.96 and 1.28 , respectively $(\mathrm{P}=0.552[t$ test $])$. The proportion of subjects with a difference of $>2$ units (considered to be a clinically meaningful decrease in pain score [13]) was considered across the treatment groups for both the three-month and the six-month data. Four of 34 (11.8\%) patients in the STC group and three of $29(10.3 \%)$ patients in the UC group had at least a 2 -unit reduction in pain after three months $(\mathrm{P}=0.858$ [Z test $])$. At six months, five of 24 (20.8\%) patients in the STC group and five of $25(20.0 \%)$ patients in the UC group had a reduction of at least 2 units $(\mathrm{P}=0.942$ [Z test] $)$.

NRS worst pain: The mean pain scores for the worst pain experienced by patients were slightly lower, but insignificant, for the STC group at three months after exposure to the intervention $(0.61$ mean score reduction in the STC group and 0.10 in the UC group $[\mathrm{P}=0.211])$. At six months, the mean reduction was 0.38 and 0.93 , respectively $(\mathrm{P}=0.362)$.

NRS least pain: The largest reduction in the least amount of pain experienced by patients occurred between baseline and six months for both groups, and was similar for the STC and UC groups; the mean reduction at three months was 0.86 for the STC group and 0.74 for the $\mathrm{UC}$ group $(\mathrm{P}=0.775)$. At six months, the mean reduction in score for the least amount of pain was 0.92 and 0.78 , respectively $(\mathrm{P}=0.796)$.

NRS current pain: Reduction in current pain was greater, but insignificant, at three months for the STC group at 1.18 and 0.55 for the $\mathrm{UC}$ group $(\mathrm{P}=0.180)$. At six months, the mean reduction in current pain scores were 0.83 and 0.84 , respectively $(\mathrm{P}=0.991)$.

Patient global perception of change: Only 47 patients responded to this question (23 from the STC group and 24 from the UC group), and no statistically significant differences were observed according to a one-sided Mann-Whitney $U$ test $(P=0.566)$. Additionally, the proportion of patients indicating 'much improved' or 'very much improved' was considered according to intervention group. In the STC group, eight of 23 patients indicated substantial improvement, compared with three of 24 patients in the UC group $(\mathrm{P}=0.072)$. To further investigate this, a logistic regression model was considered, again, yielding a treatment effect that was insignificant $(\mathrm{P}=0.082)$.
TABLE 2

Primary care physician response to standard telephone consultation

\begin{tabular}{lc}
\hline & Response \\
\hline Q1a: Convenient $(n=36)$ & $86.1(70.5-95.3)$ \\
Q1b: Timely for patient care $(n=34)$ & $94.1(80.3-99.3)$ \\
Q1c: Efficient use of your time $(n=33)$ & $93.9(79.8-99.3)$ \\
Q2: Answer your questions $(n=35)$ & $97.1(85.1-99.9)$ \\
Q3: Will you follow the recommendations? & $97.1(85.1-99.9)$ \\
$\quad(n=35)$ & \\
Q4: Help me care for my patient? $(n=35)$ & $28.6(N / A)$ \\
$\quad$ Strongly agree & $68.6(N / A)$ \\
$\quad$ Agree & $2.8(N / A)$ \\
$\quad$ Undecided & $97.1(84.7-99.9)$ \\
Q5: Recommend to colleagues? $(n=34)$ &
\end{tabular}

Data presented as \% (95\% Cl). N/A Not available

Therefore, it could not be concluded that STCs improved pain control from the perspective of the patient.

PDI: A downward, but insignificant, trend in PDI score was observed for the STC group, while the UC group remained relatively constant over the study period. The reduction in disability at three months (calculated as PDI baseline - PDI three months) was 2.69 in the STC group and -0.47 in the UC group (ie, $\mathrm{PDI}$ increased) $(\mathrm{P}=0.319)$. The reduction at six months was 4.73 and 2.5 , respectively $(\mathrm{P}=0.479)$.

SF-36 physical health dimension: For the SF-36 physical dimension, the increase at three months was 2.21 in the STC group and 1.66 in the UC group $(\mathrm{P}=0.693)$. At six months the increase was 2.07 and 2.64, respectively $(\mathrm{P}=0.747)$. Neither increase was statistically significant.

SF-36 mental health dimension: For the SF-36 mental dimension scores, uniform decreases were observed indicating worsening mental health status in both groups. The reduction at three months was 2.34 in the STC group and 3.18 in the UC group $(P=0.719)$. At six months the reduction was 0.81 and 3.52 , respectively $(\mathrm{P}=0.399)$.

\section{Is it acceptable?}

Knowledge transfer related to evidence-based practice: Based on the exact binomial distribution, it can be reported with 95\% confidence that the proportion of PCPs in the STC group affirming their experience of evidence-based learning (either agree or strongly agree) was between $63.1 \%$ and $91.6 \%$.

Primary care physician satisfaction with STC process and outcomes: Table 2 presents the responses by PCPs in the STC group to questions about the process and outcomes of the intervention, along with the corresponding binomial exact CIs. These indicate substantial support for STCs in clinical practice.

Do the resource requirements of the CPC change?

Resource utilization: To estimate whether the availability of STCs reduced the consumption of $\mathrm{CPC}$ resources compared with resources used by patients receiving UC, the time spent in direct and indirect $\mathrm{CPC}$ staff contact was calculated (Figure 2). CPC resource utilization with reference to pain specialists and other CPC team members (nursing, psychology, occupational therapy, physiotherapy, social work, kinesiology etc) for direct care, indirect care and for total care was similar for both the STC and UC groups. No reduction in resource utilization in association with STC use was evident.

\section{DISCUSSION}

Structured telephone consultations between pain specialists and PCPs were very well received by recipients as a knowledge transfer strategy, and were perceived as contributing to improved quality of care. However, no statistically significant differences in patient outcomes were observed between the STC and UC groups.

There are a number of possible explanations for this discrepancy. The failure to fully recruit the intended sample caused the study to be 


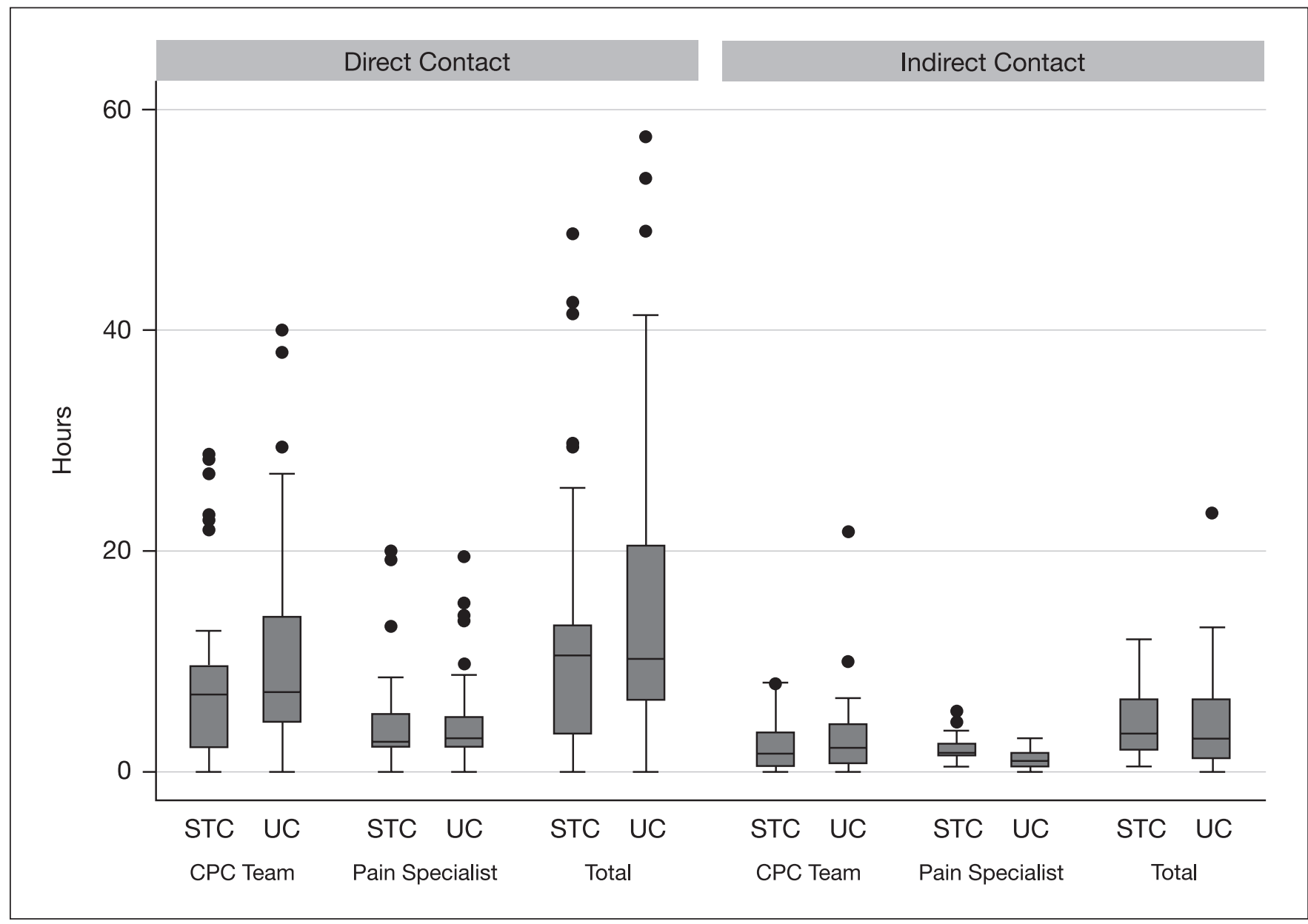

Figure 2) Chronic Pain Centre (CPC) resource utilization. Boxplots provide the median (centre line), first (lower box edge) and third (upper box edge) quartiles, as well as the upper and lower adjacent values (at the end of each whisker). Dots represent values $>1.5 \times$ the interquartile range away from the median. STC Standard telephone consultation; UC Usual care

underpowered. This is supported by the tendency of the STC group to have more positive average outcome scores than the control (ie, UC) group. The wide variability in individual scores diminishes the likelihood of detecting group differences in an underpowered study and highlights the inconsistency of response to the treatment plan. The lack of significant benefit for STC patients may be related to inconsistent exposure to the recommended treatments. It is possible that the recommendations were not carried out, either because the PCP or the patient objected, or because the patient did not return to see the PCP in time for the possible benefits of treatment to be observed when follow-up occurred. It is also possible that when the treatment plan called for sequential titrated medication trials or patient participation in community-based self-management education, the three and six month follow-up intervals were not synchronized to capture the treatment effects that may have occurred. It is also feasible that the pain management introduced by PCPs ahead of any specialist consultation was, in practice, as effective as that recommended by the pain specialists.

However, the strong response from PCPs in favour of telephone consultation indicates that the intervention may have merit. Chronic pain is notoriously difficult to treat. Duration of pain has a significant effect on the likelihood of therapeutic response, and more timely advice regarding treatment may be helpful to PCPs. The ability to obtain quick reassurance that one is doing all one reasonably can to assuage the problem is understandably beneficial, and may lead to service efficiencies if it reduces unnecessary referrals and empowers PCPs to manage pain without pain specialist intervention. More strategically, telephone consultations involve a specialist and a generalist engaging in a learning process that may be transferred to similar cases and circumstances. In addition, telephone consultations potentially require less investment in scheduling, travel, office resources and compensation-related issues than conventional referral, and have potential to be a widely available and easily accessible resource.

Future studies should consider a detailed health economic analysis of different types of consultation processes, and should consider other options for communicating with PCPs such as eConsult (17) and faxing recommendations (18) to PCPs.

\section{SUMMARY}

The present trial demonstrated that structured telephone consultations between pain specialists and PCPs are a well accepted strategy for communicating evidence-based approaches regarding chronic pain management and leads to conditions of equipoise in patient clinical health status when compared with patients undergoing usual care. Standard telephone consultations for PCPs continue to be offered by the Calgary CPC and have become a standard of care.

FUNDING: Alberta Heritage Foundation for Medical Research (currently Alberta Innovates - Health Solutions)

DISCLOSURES: The authors have no financial relationships or conflicts of interest to declare. 


\section{REFERENCES}

1. Breivik H, Collett B, Ventafridda V, Cohen R, Gallacher D. Survey of chronic pain in Europe: Prevalence, impact on daily life, and treatment. Eur J Pain 2006;10:287-333.

2. Schopflocher D, Taenzer P, Jovey R. The prevalence of chronic pain in Canada. Pain Res Manag 2011;16:445-50.

3. Schopflocher DP. Chronic Pain in Alberta: A portrait from the 1996 National Population Health Survey and the 2001 Canadian Community Health Survey. Alberta Health and Wellness Public Report, Edmonton, Alberta. <www.health.alberta.ca/documents/ Chronic-Pain-Survey-2003.pdf> (Assessed February 3, 2014).

4. Upshur CC, Luckmann RS, Savageau JA. Primary care provider concerns about management of chronic pain in community clinic populations. J Gen Intern Med 2006;21:652-5.

5. Chelimsky TC, Fischer RL, Levin JB, Cheren MI, Marsh SK, Janata JW. The primary practice physician program for chronic pain (C) 4PCP): Outcomes of a primary physician-pain specialist collaboration for community-based training and support. Clin J Pain 2013;29:1036-43.

6. Watt-Watson J, McGillion M, Hunter J, et al. A survey of prelicensure pain curricula in health science faculties in Canadian universities. Pain Res Manag 2009;14:439-44.

7. Peng P, Choiniere M, Dion D, et al. (STOPPAIN Investigators Group). Challenges in accessing multidisciplinary pain treatment facilities in Canada. Can J Anesth 2007;54:977-84.

8. Norlund A, Ropponen A, Alexanderson K. Multidisciplinary interventions: Review of studies of return to work after rehabilitation for low back pain. J Rehabil Med 2009;41:115-21.

9. Tunks E. Multidisciplinary Pain Clinic Treatment. In: Rashiq S, Schopflocher D, Taenzer P, Jonsson E, eds. Chronic Pain: A Health
Policy Perspective. Weinheim, Germany: Wiley-VCH Verlag, 2008:141-52.

10. Lynch ME, Campbell F, Clark,AJ, et al. A systematic review of the effect of waiting for treatment for chronic pain. Pain 2008;136:97-116.

11. Golub RM. Curbside consultations and the viaduct effect. JAMA 1998;280:929-30.

12. Kuo D, Gifford DR, Stein MD. Curbside consultation practices and attitudes among primary care physicians and medical subspecialists. JAMA 1998;280:905-9.

13. Farrar JT, Young JP, LaMoreaux L, Werth JL, Poole M. Clinical importance of changes in chronic pain intensity measured on an 11-point numerical pain rating scale. Pain 2001;94:149-58.

14. Tait RC, Pollard CA, Margolis RB, Duckro PN, Krause SJ. The pain disability index: Psychometric and validity data. Arch Phys Med Rehab 1987;68:438-41.

15. McHorney CA, Ware JE, Raczek AE. The MOS 36-item ShortForm Health Survey (SF-36): Psychometric and clinical tests of validity in measuring physical and mental health constructs. Med Care 1993;31:247-63.

16. Evans CJ, Trudeau E, Mertzanis P, et al. Development and validation of the Pain Treatment Satisfaction Scale (PTSS): A patient satisfaction questionnaire for use in patients with chronic or acute pain. Pain 2004;112:254-66.

17. Keely E, Liddy C, Afkham A. Utilization, benefits, and impact of an e-consultation service across diverse specialties and primary care providers. Telemed J E Health 2013;19:733-8.

18. Clark AJ, Beauprie I, Clark LB, Lynch ME. A triage approach to managing a two year wait-list in a chronic pain program. Pain Res Manag 2005;10:155-7. 


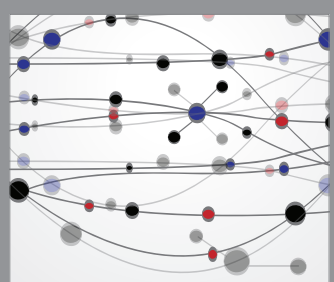

The Scientific World Journal
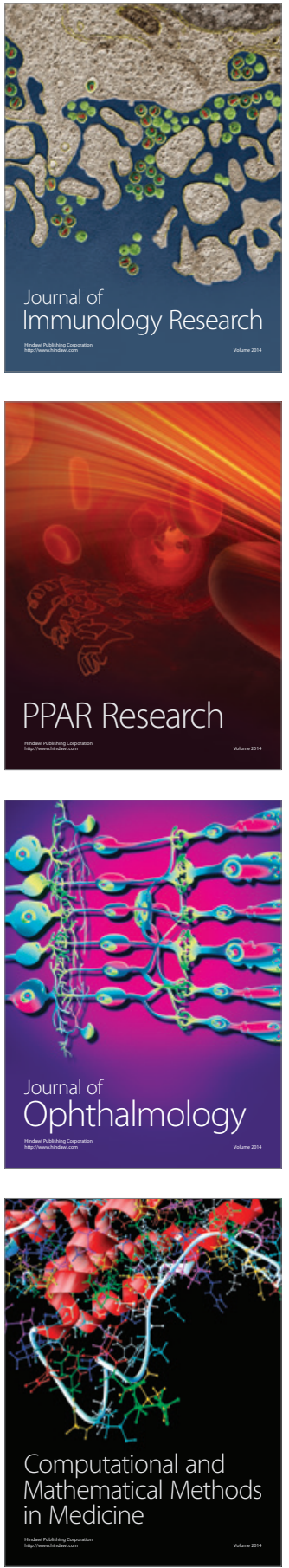

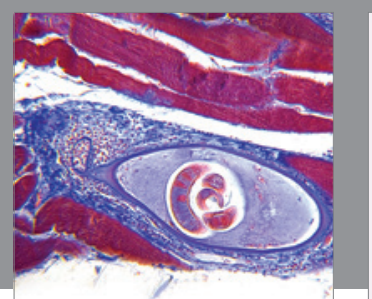

Gastroenterology Research and Practice

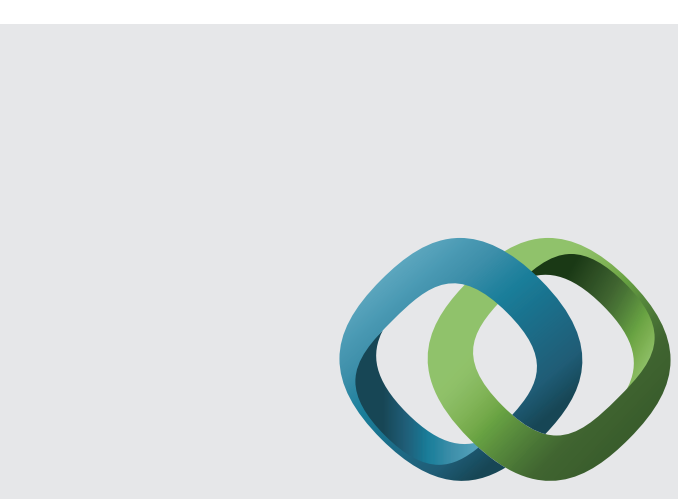

\section{Hindawi}

Submit your manuscripts at

http://www.hindawi.com
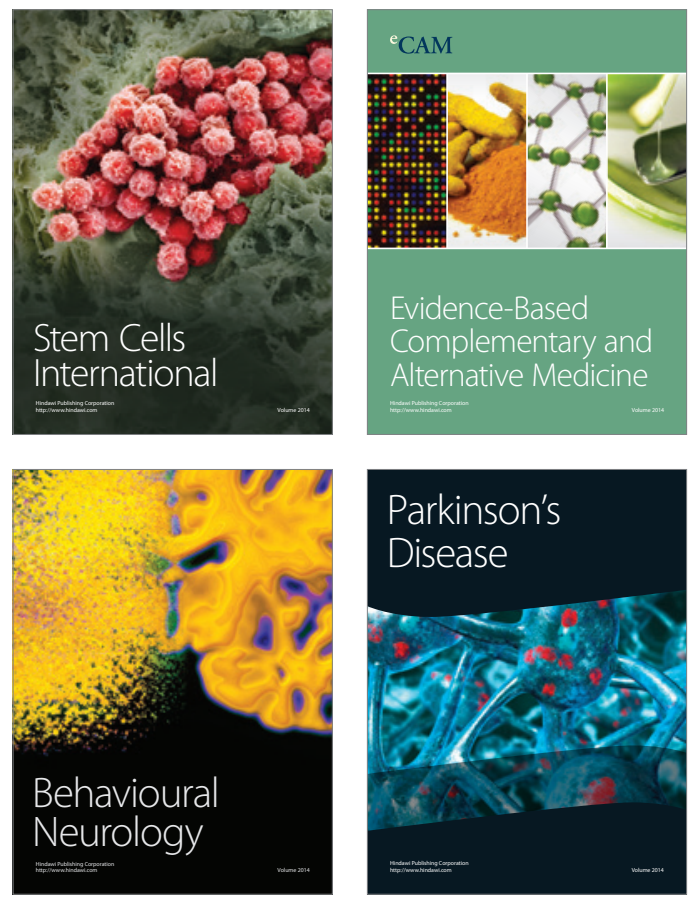
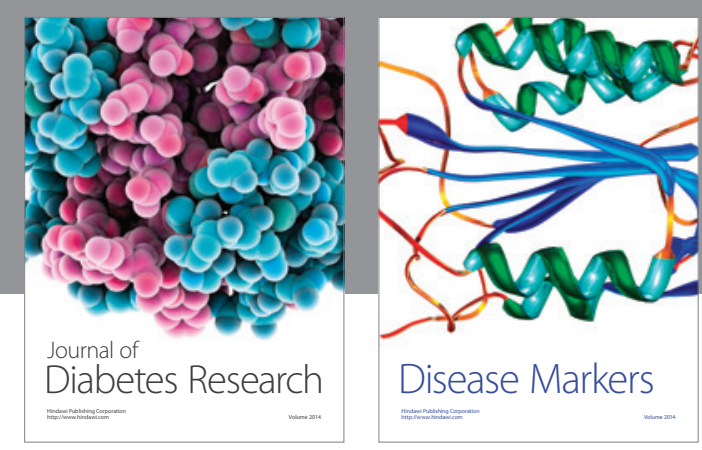

Disease Markers
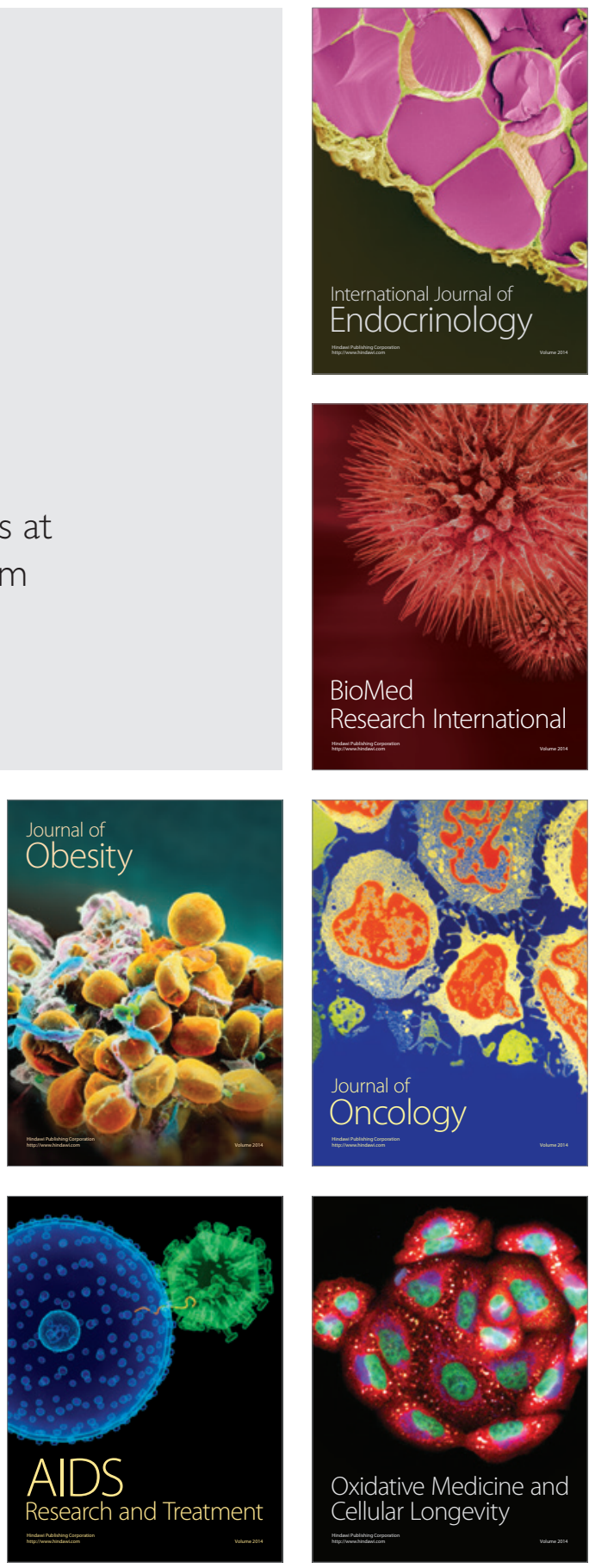